\title{
The Fitness Status of German Managers and Executive Employers: A Study of Self-Perception and Reality
}

\author{
By Diana Jedlicka* \\ Hans-Georg Predel ${ }^{\dagger}$
}

\begin{abstract}
The adoption of a health-oriented lifestyle by executive managers is an important factor influencing the success of an entire company. To the best of our knowledge, no study has investigated self-reported health and fitness statuses among managers and compared them with objectively measured parameters based on standardized exercise tests. Thus, the purpose of this study was to evaluate the congruence of the selfperceived and objectively measured health statuses of managers. Data for the retrospective cross-sectional study of 54 managers (51 males, 3 females, age: $46.1 \pm$ 7.0 years, BMI $26.0 \pm 3.2 \mathrm{~kg} / \mathrm{m} 2$ ) were collected through medical health check-ups. Besides the measurement of medical data, the managers estimated their own fitness and health in a questionnaire. The differences and associations between self-reported and objective measures (endurance and strength performance as measured through a to-exhaustion ergometer test and $\mathrm{VO}_{2} \max$ ) were analyzed. Subsequently, the cohort was divided into four groups: realistic inactives, realistic actives, underestimators and overestimators. Significant associations were found between $\mathrm{VO}_{2}$ max and self-rated endurance capacity $(r=0.41)$ and between performance, reached in the to-exhaustion ergometer test, and self-estimated strength $(r=0.29)$. The majority of subjects rated their endurance capacity (69\%) and strength (65\%) realistically with a tendency towards underestimation. The present study revealed that most managers had a satisfying health status and were able to rate their own physical endurance and strength performance correctly, with a tendency towards underestimation. These findings are important for prevention and health promotion programs for managers.
\end{abstract}

Keywords: Fitness status, managers, self-rating, performance test, health.

\section{Introduction}

Physical fitness confers both a prevention and protection effect against cardiovascular disease. The assessment of physical fitness can be a complicated procedure and it is not always standardized. Given this, it is important to consider socioeconomic and educational factors when determining whether self-perception is associated with objectively measured health and fitness parameters. Holtermann et al. (2015) showed in the Copenhagen City Heart study that higher self-rated cardiovascular fitness correlated significantly with lower mortality. Thus, this

\footnotetext{
*Research Assistant, German Sport University Cologne, Germany.

†Professor and Head of the Institute of Cardiology and Sports Medicine, German Sport University Cologne, Germany.
} 
self-assessment is an important, independent prognostic parameter that could increase risk stratification in primary prevention.

Relating this issue to executives, the success of a company is often related to the adoption of a health-oriented lifestyle by managers. It is well known that, in particular, managers tend to overestimate their own abilities and skills (for example, in areas such as leadership competency), as well as supporting a realistic self-image of safe and healthy leadership of employees. As such, if managers could estimate their own health and fitness correctly, it would have several advantages and positive effects for themselves, their employees, and the company. A health-conscious manager might have better leadership characteristics, focus more on employee well-being and be more willing to invest in professional worksite health promotion programs (Hayward et al. 2004). Based on this background, this study investigates the congruency of self-ratings and objective health values in the cohort of managers.

\section{Literature Review}

\section{Health Orientation in Managers}

It is well established that the valuation and promotion of health-related aspects in modern companies are essential for employers' and employees' performance and well-being (Jung et al. 2012, Schulte et al. 2015). Thus, the success of the company is, amongst other things, dependent on the adoption of a health-oriented lifestyle by executive managers. They act not only as a supervisor, but also as a motivator and idol. In particular, it is the group of managers that tends to work under consistent time pressure and permanent availability (Dunning et al. 2004, Plante and Bouchard 1996). For executive managers in this capacity, a high level of self-esteem is essential for success in their careers, but may also potentially result in overestimations of their own abilities and behavior (Dunning et al. 2004, Malmendier and Tate 2003). To rate one's own skills and abilities accurately is difficult, and misperceptions might have serious consequences, especially for chief executive officers (CEOs). However, no analysis has been carried out thus far on whether managers can appropriately perceive their own health and fitness realistically.

\section{Overrating as a Common Phenomenon}

There is a general tendency towards an overestimation of one's own capabilities in the general population (Dunning et al. 2004, Fischhoff et al. 1977). Previous studies have reported that inaccurate self-assessments not only take place in laboratory experiments, but also in real-world settings, such as private life and work. This may concern one's own skills (e.g. leadership, job performance), future behaviors (e.g. quit smoking, exercise more), business development (e.g. reaching desirable outcomes, economic growth) or medical issues (e.g. health status, personal fitness) (Dunning et al. 2004). The potential 
reasons for this overestimation are varied and include: a desire to give positive impressions and avoid negative images of themselves (Baumeister and Newman 1994, Dunning 2001), the so-called above-average effect (Odean 1998, Friedrich 1996), the overconfidence effect (Dunning and Story 1991, Fischhoff et al. 1977), or perceptions of uniqueness, consensus or psychological mechanisms being used as means to hide a lack of expertise or incompetence (Dunning et al. 2004).

Overconfidence or overestimation of abilities has the greatest impact on tasks that are difficult, forecasts where the outcome has a low predictability, and undertakings that lack fast and clear feedback (Barber and Odean 2000). Such effects are also relevant to health issues, though they have been studied in a different manner. For example, comparable results for overrating on complex health-related topics exist regarding the documentation of fruit or vegetable consumption (Lechner et al. 2006, Lechner, Brug and De Vries 1997).

\section{Self-ratings as a Tool in Research}

Past research on the self-evaluations of one's cardiovascular and muscular fitness has shown positive agreements with practical, physiological testing methods (Borodulin et al. 2006, Keith et al. 2014, Ortega et al. 2013, Holtermann et al. 2015, Ronda et al. 2001, Mabe and West 1982, Martinez-Gomez et al. 2012, Aadahl et al. 2007, Mikkelsson et al. 2005). Monroe et al. (2010) reported statistically significant associations between self-reported and measured cardiorespiratory fitness, muscular fitness and flexibility, using the Physical Self-Description Questionnaire (Marsh 1996). Similarly, Holtermann et al. (2015) evaluated data from more than 8000 participants concerning mortality, longevity and self-reported cardiorespiratory fitness as related to instances of cardiovascular disease as part of the Copenhagen City Heart Study. Their results showed that self-rated fitness and health status were significantly correlated with the study's objectively measured values. Thus, self-reported cardiorespiratory fitness as an independent prognostic parameter is related to a considerable survival benefit and might be helpful for improving risk stratification in primary prevention. However, in this same study by Holtermann et al. (2015), the questionnaire regarding cardiorespiratory fitness was not validated against an objective measurement using exercise testing.

Aadahl (2007) compared the $\mathrm{VO}_{2}$ max of 102 Danish adults with their selfassessed physical activity levels and found that the amount of daily intense activity $\left(>6\right.$ MET) was strongly correlated with $\mathrm{VO}_{2} \max \left(\mathrm{P}=<0.01, \mathrm{R}^{2}=\right.$ 0.76 ), whereas the total volume of daily physical activity showed a slight, but not statistically significant, connection with $\mathrm{VO}_{2} \max \left(\mathrm{p}=0.10, \mathrm{R}^{2}=0.69\right)$. Based on these measures, they stated that subjects were capable of estimating their own fitness quite precisely.

\section{Purpose of the Study and Research Questions}

To the best of our knowledge, there has not been a previous study investigating self-reported health and fitness statuses among managers and 
comparing them with objectively measured parameters based on standardized exercise tests. Self-ratings concerning health and fitness parameters measured via questionnaires may give supplemental, valuable information in addition to objective measurements via exercise tests. New findings, together with those from previous studies, examine the usefulness and potential of self-estimations as tools in occupational and public health contexts. Therefore, it is the purpose of the study to compare measured and self-estimated health statuses of managers. In accordance with previous studies, it is hypothesized that managers tend to overrate their own health and fitness capacities.

To achieve the purpose of this study, the authors examined the following research questions:

(1)How do executive managers rate their own fitness and health in comparison with objectively measured health data?

(2)Is there an association between self-rated endurance and $\mathrm{VO}_{2} \mathrm{max}$, as well as between self-rated strength and performance in a to-exhaustion ergometer test?

Methodology

Subjects

Fifty-four managers (51 males, 3 female, age: $46.1 \pm 7.0$ years, BMI 26.0 $\pm 3.2 \mathrm{~kg} / \mathrm{m}^{2}$ ) from the first or second hierarchy within a senior working level were recruited from major national and international enterprises with 850 to 330,000 employees. They underwent health check-ups at the German Sport University in Cologne, Germany. In the context of this medical screening process, all subjects were thoroughly examined prior to exercise performance tests.

\section{Study Design}

Medical data for the study were collected between 2012 and 2016 by researchers of the Institute of Cardiology and Sports Medicine at the German Sport University in Cologne. For the purposes of this paper, these were analyzed retrospectively. In addition to the assessment of medical data (anthropometric values, fitness exhaustion test, sports medical examinations), subjects completed a questionnaire concerning their health, fitness and involvement in leisure time physical activities and recreational and/or competitive sports.

\section{Ethics}

The local ethics committee of the German Sport University in Cologne, Germany (Number: 099-2016, DRKS registration number: DRKS00010986) has approved the present study, which was conducted in compliance with the Declaration of Helsinki 1964. All subjects provided informed written consent prior to participation in the study and agreed to anonymous use of their data. 
The participation was voluntary, and withdrawal was possible at any time without any disadvantages for the subject.

\section{Instruments Measuring Physical Activity}

Physical Work Capacity (PWC), as shown by the performance levels reached during the bicycle ergometer test, was measured in Watts (W) and assessed by an incremental, stepwise increase in the workload until exhaustion (Ergometrics 900, Ergoline GmbH, Bitz, Germany). The fitness test used in this study has been shown to be valid and reliable (Vassiliadis 1999). The workload started with $30 \mathrm{~W}$ and was increased every $3 \mathrm{~min}$ by $40 \mathrm{~W}$ without pauses. The reference values used were based on healthy untrained participants and were $3.0 \mathrm{~W} / \mathrm{kg}$ for men 20-30 years of age, with a decrease of $10 \%$ for every subsequent decade, and $2.5 \mathrm{~W} / \mathrm{kg}$ for women 20-30 years of age, with a decrease of $8 \%$ for every subsequent decade (Tanakaet al. 2001).

Endurance and performance in this study were measured by absolute $\mathrm{VO}_{2}$ max $(\mathrm{ml} / \mathrm{min})$ and relative $\mathrm{VO}_{2} \mathrm{max}(\mathrm{ml} / \mathrm{min} / \mathrm{kg})$, respectively. The software AMEDTEC ECGpro® v.3.66 (AMEDTEC Medizintechnik Aue GmbH, Aue, Germany) was used to analyze this data. $\mathrm{VO}_{2} \mathrm{max}$ was analyzed via spiroergometry with simultaneous measurement of breath-to-breath oxygen intake in 15-second periods $\left(Z_{A N}{ }^{\mathrm{TM}}\right.$ Messgeräte $\mathrm{GmbH}$ Deutschland, Oberthulba, Germany). These measures were evaluated via the software Cardio-Pulmonale Funktions-Diagnostik Software (nSpire Health GmbH, Oberthulba, Germany). Reference values concerning personal endurance and performance determined via relative $\mathrm{VO}_{2}$ max have been published elsewhere (Fletcher et al. 1995).

\section{Measurements of Self-Reports}

Subjects gave information about their leisure time physical activities in a medical anamnesis history and subjectively estimated their general health and fitness status on a Likert scale using a standardized questionnaire. Validation of a questionnaire as a tool revealed a reliability of 0.7 (Cronbachs Alpha) (Jedlicka et al. n.d.), a mean item discriminatory power of 0.3 (range $0.1-0.8$ ) and an item difficulty of 73.3 (range 49.8-79.4). The question used in this study was as follows: "How do you estimate your current health status and, in particular, your endurance and strength performance on a scale from 1 (very bad) to 10 (excellent)?"

\section{Statistical Analyses}

Statistical analyses were performed with SPSS Statistics 24 (IBM, Armonk, USA). All data are described in terms of mean, standard deviation of the mean, MIN for minimum values, MAX for maximum values, numbers and percentages.

Differences between self-reported (endurance, strength) measures and and objective data $\left(\mathrm{VO}_{2} \mathrm{max}\right.$, ergometer performance) were tested via the Mann- 
Whitney-U-Test, and associations were identified via the Spearman correlation coefficient.

Based on the results of the objectively measured $\mathrm{VO}_{2}$ max and ergometer performance, subjects were assigned into two groups: "fit" and "unfit." These were determined based on whether subjects reached gender and age specific reference values for relative $\mathrm{VO}_{2} \max (\mathrm{ml} / \mathrm{min} / \mathrm{kg}$ ) (Fletcher et al. 1995) or relative performance $(\mathrm{W} / \mathrm{kg}$ ) (Tanakaet al. 2001) during the exhaustion test. The self-ratings via questionnaire also divided subjects into two groups. Answers were possible from 1 (very bad) to 10 (excellent) concerning one's won endurance and strength. "Fit" refers to ratings from 6-10, while "unfit" refers to ratings from 1-5. By doing this, subjects were grouped into a $2 \times 2$ table based upon the agreement between their self-rated and objective physical activity measures. This resulted in four awareness groups: realistic inactives, realistic actives, overestimators and underestimators (Table 2, Table 3 ). The difference between overestimators and underestimators was calculated via McNemar's Chi-square (Binomial Test) test. A value of $p<0.05$ was considered significant (Bortz 2005).

\section{Findings and Results}

In total, 54 subjects participated in the study. The participants' medical data are presented in Table 1. Forty-eight managers stated that they are active in sports $(89 \%)$, with most of them reporting between one and six hours of activity per week $(\mathrm{M}=5.5, \mathrm{SD}=3.5)$. These activities mainly included endurance sports and strength training.

Table 1. Medical Data of Subjects

\begin{tabular}{|c|c|c|}
\hline Variables & $\mathrm{M}$ & SD \\
\hline Age [years] & 46.1 & 7.0 \\
\hline Body height $[\mathrm{cm}]$ & 181.3 & 6.1 \\
\hline Body weight $[\mathrm{kg}]$ & 85.2 & 13.9 \\
\hline BMI $\left[\mathrm{kg} / \mathrm{m}^{2}\right]$ & 26.0 & 3.2 \\
\hline Waist circumference $[\mathrm{cm}]$ & 92.4 & 11.9 \\
\hline Absolute ergometer performance [W] & 224.7 & 39.9 \\
\hline Relative ergometer performance [W/kg] & 2.7 & 0.5 \\
\hline $\mathrm{PWC}_{130}[\mathrm{Watt} / \mathrm{kg}]$ & 1.7 & 0.6 \\
\hline $\mathrm{PWC}_{150}[\mathrm{Watt} / \mathrm{kg}]$ & 2.1 & 0.7 \\
\hline Absolute $\mathrm{VO}_{2} \max [\mathrm{ml} / \mathrm{min}]$ & 3.1 & 0.6 \\
\hline Relative $\mathrm{VO}_{2} \max [\mathrm{ml} / \mathrm{min} / \mathrm{kg}]$ & 35.9 & 6.5 \\
\hline Self-rated health status [points] & 7.9 & 1.5 \\
\hline Self-rated endurance [points] & 5.8 & 2.0 \\
\hline Self-rated quality of life [points] & 8.4 & 1.2 \\
\hline Self-rated strength [points] & 6 & 2 \\
\hline Sports activity [hours per week] & 5.5 & 3.5 \\
\hline
\end{tabular}

Concerning performance diagnostics, the mean absolute performance reached in the to-exhaustion ergometer test was $224.7 \mathrm{~W}$ ( $\mathrm{SD}=39.9)$, whereas the mean relative ergometer performance was $2.7 \mathrm{~W} / \mathrm{kg}(\mathrm{SD}=0.5), \mathrm{PWC}_{130} 1.7 \mathrm{~W} / \mathrm{kg}$ 
$(\mathrm{SD}=0.6)$ and $\mathrm{PWC}_{150}$ was $2.1 \mathrm{~W} / \mathrm{kg}(\mathrm{SD}=0.7)$. It was found that $78 \%$ of the subjects reached at least their age and gender specific reference values concerning their individual performance. The mean absolute $\mathrm{VO}_{2}$ max was $3.1 \mathrm{ml} / \mathrm{min}$ (SD $=0.6)$ and relative $\mathrm{VO}_{2} \max$ was $35.9 \mathrm{ml} / \mathrm{min} / \mathrm{kg}(\mathrm{SD}=6.5)$. Eleven subjects $(20 \%)$ did not reach their age and gender specific reference values for relative $\mathrm{VO}_{2} \max$ (Table 1).

The means of the subjects' self-ratings were $5.8(\mathrm{SD}=2.0)$ regarding endurance performance and $6.0(\mathrm{SD}=2.0)$ regarding strength. The descriptive results of parameters used for the correlation analysis are described in Table 1. There were eight subjects who did not want to complete the questions for personal reasons.

In regard to self-assessed endurance, the differences between groups (objectively "fit" versus "unfit" for relative $\mathrm{VO}_{2} \max$ ) were tested. Data revealed a statistically significant difference between objectively "fit" $(6.3 \pm 1.8)$ and "unfit" $(4.5 \pm 2.4)$ participants $(p=0.02)$. Data concerning relative ergometer performance were also significantly different between objectively "fit" 6.3 ( \pm $2.1)$ and "unfit" $5.1( \pm 1.4)(\mathrm{W} / \mathrm{kg})(\mathrm{p}=0.049)$.

Spearman rank correlation reflected significant associations $(p<0.05)$ between objectively measured and self-rated parameters of health and fitness. Correlations with significance at a level of 0.01 (both sides) were self-rated endurance (points) and relative $\mathrm{VO}_{2} \mathrm{max}(\mathrm{ml} / \mathrm{min} / \mathrm{kg})$ with $\mathrm{r}=0.4$ and self-rated endurance (points) and relative ergometer performance (W) with $r=0.5$. Correlations with significance at a level of 0.05 (both sides) were self-rated endurance (points) and absolute ergometer performance (W) with $\mathrm{r}=0.3$, selfrated strength (points) and absolute ergometer performance (W) with $\mathrm{r}=0.4$, and self-rated strength (points) and relative ergometer performance (W) with $\mathrm{r}=0.3$. There were no significances for the absolute $\mathrm{VO}_{2} \max$.

Table 2 shows the classification of subjects into four awareness groups for endurance and $\mathrm{VO}_{2} \max$. It was found that $69 \%$ of the subjects rated correctly whether or not they reached gender and age specific reference values for endurance based on relative $\mathrm{VO}_{2} \mathrm{max}(51 \%$ realistic assessment of being "fit", $18 \%$ realistic assessment of being "unfit"). Furthermore, eleven participants (24\%) who also reached the age and gender specific reference values classified themselves as "unfit" (underestimators). There were three participants (7\%) who overestimated their objective endurance performance by missing their age and gender specific reference values. The difference concerning their endurance capacity between overestimators and underestimators was not significant $(\mathrm{p}=$ $0.06)$. 
Table 2. Classification of Participants into Awareness Groups for Endurance and $\mathrm{VO}_{2} \max (n=45)$

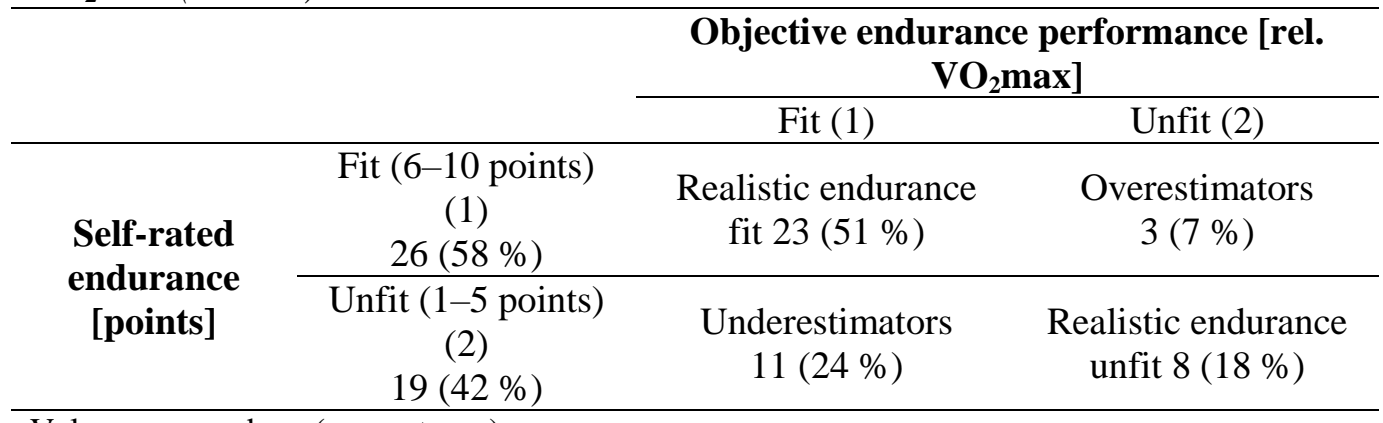

Values are numbers (percentages).

Table 3 shows the classification of subjects into four awareness groups for strength and ergometer performance. Data revealed that $65 \%$ of the subjects correctly rated whether or not they reached gender and age specific reference values for relative ergometer performance (50\% realistic assessment of being "fit", 15\% realistic assessment of being "unfit"). Furthermore, twelve participants (26\%) who reached the age and gender specific reference values classified themselves as "unfit" (underestimators), and four participants (9\%) overestimated their objective ergometer performance strength by missing their age and gender specific reference values (overestimators). The difference concerning their strength capacity between overestimators and underestimators was not significant $(\mathrm{p}=0.08)$.

Table 3. Classification of Participants into Awareness Groups for Self-Rated Strength and Ergometer Performance $(n=46)$

\begin{tabular}{|c|c|c|c|}
\hline & & \multicolumn{2}{|c|}{$\begin{array}{l}\text { Objective ergometer performance [Watt / } \\
\text { kg] }\end{array}$} \\
\hline & & Fit (1) & Unfit (2) \\
\hline \multirow{2}{*}{$\begin{array}{l}\text { Self-rated } \\
\text { strength } \\
\text { [points] }\end{array}$} & $\begin{array}{c}\text { Fit (6-10 points) } \\
(1) \\
27(59 \%)\end{array}$ & $\begin{array}{c}\text { Realistic ergometer } \\
\text { performance fit } \\
23(50 \%)\end{array}$ & $\begin{array}{c}\text { Overestimator } \\
4(9 \%)\end{array}$ \\
\hline & $\begin{array}{c}\text { Unfit (1-5 points) } \\
\text { (2) } \\
19(41 \%)\end{array}$ & $\begin{array}{l}\text { Underestimator } \\
12(26 \%)\end{array}$ & $\begin{array}{c}\text { Realistic ergometer } \\
\text { performance unfit } 7 \\
(15 \%)\end{array}$ \\
\hline
\end{tabular}

Values are numbers (percentages).

\section{Discussion}

Parameters related to performance diagnostics such as the Physical Work Capacity (ergometer performance in Watt) or maximal oxygen consumption $\left(\mathrm{VO}_{2} \mathrm{max}\right.$ in $\mathrm{ml} / \mathrm{min}$ ) have not been evaluated previously in this cohort. Thus predictions for this project were made based on other previous research. Particularly, in accordance with previous psychologically-oriented studies in this field of research, it was hypothesized that managers would overrate their fitness and health status in self-reports compared to objectively determinable 
values. Against the initial hypothesis, however, the data showed that the majority of managers in this study made realistic estimates concerning their fitness and health, with a tendency even towards underestimation.

Overall, this study revealed that the majority of managers had a satisfying health status as shown by reaching their age and gender specific reference values for endurance and strength measures $\left(75 \%\right.$ relative $\mathrm{VO}_{2} \max , 76 \%$ relative ergometer performance). In this study, the majority of managers estimated their endurance and strength performance realistically, having only a small percentage of overestimators ( $7 \%$ for self-rated endurance performance, $9 \%$ for self-rated strength). Furthermore, correlations showed positive associations between relative $\mathrm{VO}_{2} \mathrm{max}$ and self-rated endurance performance $\left(\mathrm{r}_{\mathrm{SP}}(44)=0.41, \mathrm{p}<0.01\right)$, as well as for the relative ergometer performance and self-rated strength performance $\left(\mathrm{r}_{\mathrm{sp}}(46)=0.29, \mathrm{p}<0.05\right)$.

In the literature, between $40 \%$ and $65 \%$ of the individuals in the general population overestimated the amount of their physical activity (Ronda et al. 2001, Lechner et al. 2006, van Sluijs et al. 2007, Watkinson et al. 2010), indicating that physical activity misperception is a common phenomenon. Again, only questionnaires and no objective assessments had been used in this past research. Schaller et al. (2016), Rudolf et al. (2016) and Prince et al. (2008) found similar results.

Similar analyses showcasing tendencies towards overestimations were also made by Godino et al. (2014) who analyzed data of 453 middle-aged men from a population-based, observational study. In that study, the self-rated physical activity was measured dichotomously by asking participants if they believed they were achieving the age and gender specific recommended level of physical activity, while answers were compared to objective physical activity afterwards. It was found that $29 \%$ overestimated their objective physical activity level, reflecting a stronger tendency towards overrating.

On the other hand, Ortega et al. (2013) compared self-perceived versus measured fitness to predict cardiovascular disease (CVD) risk and validated the International Fitness Scale (IFIS). The questionnaire revealed not only a good correlation between self-perceived and objectively measured fitness (field-based fitness tests and $20 \mathrm{~m}$ shuttle-run test), but also a strong association between a high self-perceived fitness level with a good cardiovascular prognosis. The correlations for muscular fitness (reported via questionnaire and objectively measured via handgrip test and standing long jump) were similar, although lower. The differing results obtained in this study, demonstrating rather realistic selfperceptions, might be due to the following factors:

The managers examined here were on average 46 years old and therefore belong to a generation which may have a higher tendency towards self-reflection and criticism, in contrast to older managers (Franken 2016, Kuhlmann and Horn 2016, Kienbaum Management Development 2017). It can be speculated that these managers had been in their leadership positions only for a relatively short period. In addition, measures of occupational health management, which are aimed at enhancing individual health competences, could also be responsible for the results of this study. Different organizational structures of the enterprises 
the managers work for might be a further explanation of the results of this study. It is possible that subjects of this study have already participated in specific courses offered within the company to promote their health literacy. Results from training programs or courses, e.g. leadership characteristics, perceptions or selfimages, might be transferred to various other aspects of their lives, such as health.

In our study, realistic managers and underestimators performed the highest number of weekly hours of leisure time activities and vice versa for the overestimators. The observation that physically active participants or managers with an athletic background showed greater ability to perceive their health status than inactive participants is in line with previous scientific reports (Condello et al. 2016, van Weering et al. 2011). Furthermore, participants' socio-economic backgrounds may have influenced their ability to produce a realistic self-perception (Jung et al. 2012). The managers observed in this study had rather higher socio-economic statuses, thus contributing to this capacity for accurate self-assessment.

Strengths and Limitations of the Study

$\underline{\text { Strengths }}$

The exercise tests used in this study took place between 8-11 a.m. in the morning and were carried out according to highly sophisticated and standardized techniques, guaranteeing valid results. The subjects were not influenced in their response behavior or performance in the exhaustion test. Data accuracy and reliability were enhanced by experienced, trained, medical staff in the center. This is the first study to compare self-estimated assessments with objectively measured health parameters in managers from the first or second hierarchy at a senior working level.

\section{$\underline{\text { Limitations }}$}

It is unclear whether the managers investigated in this study are representative of the total population. Furthermore, the number of female executives was quite small, though this does reflect the real situation in high-ranked management positions. A further limitation of the study is the cross-sectional design of the study, as it cannot give information about possible cause-effect relationships. It remains unclear whether the motor component force, which is assumed here, is represented in sufficient form by our tests.

\section{Conclusions}

In summary, the obtained data in this study demonstrate that the majority of managers had a satisfactory objective health status, along with the ability to realistically assess their own health and fitness statuses. Thus, self-ratings concerning health and fitness parameters measured via questionnaires may give 
supplemental, valuable information in addition to objective measurements via exercise tests. These findings, together with those from previous studies, underline the usefulness and the potential of self-estimations as a tool in occupational and public health contexts. For future research, it would be interesting to examine employees of smaller companies, as well as executives of middle management positions, since they are also prone to be physically and mentally stressed. Furthermore, female managers must be evaluated more in the future. A further strengthening of the health competency of managers and other employees is reasonable.

\section{References}

Aadahl M, Kjaer M, Kristensen JH,Mollerup B, Jorgensen T (2007) Self-reported physical activity compared with maximal oxygen uptake in adults. European Journal of Cardiovascular Prevention and Rehabilitation: Official Journal of the European Society of Cardiology, Working Groups on Epidemiology \& Prevention and Cardiac Rehabilitation and Exercise Physiology 14:422-428.

Barber BM, Odean T (2000) Boys Will Be Boys: Gender, Overconfidence, and Common Stock Investment. Quarterly Journal of Economics. Retrieved from SSRN: https:// ssrn.. com/abstract $=219240$.

Baumeister RF, Newman LS (1994) Self-Regulation of Cognitive Inference and Decision Processes. Personality and Social Psychology Bulletin, 20: 3-19.

Borodulin K, Laatikainen T, Salomaa V, Jousilahti P (2006) Associations of leisure time physical activity, self-rated physical fitness, and estimated aerobic fitness with serum C-reactive protein among 3,803 adults. Atherosclerosis 185: 381-387.

Bortz J (2005) Statistik: Für Human- und sozialwissenschaftler. [Statistics for human and social science researchers]. Wein, Springer.

Condello G, Capranica L, Stager J, Forte R, Falbo S, Di Baldassarre A et al. (2016) Physical Activity and Health Perception in Aging: Do Body Mass and Satisfaction Matter? A Three-Path Mediated Link. PloS one11, e0160805.

Dunning D (2001) On the motives underlying social cognition. In N Schwarz, A Tesser (eds), Blackwell handbook of Social Psychology. vol. 1, Intraindividual processes, 348-374. Blackwell.

Dunning D, Heath C, Suls JM (2004) Flawed Self-Assessment: Implications for Health, Education, and the Workplace. Psychological Science in the Public Interest: A Journal of the American Psychological Society 5:69-106.

Dunning D, Story AL (1991) Depression, realism, and the overconfidence effect: are the sadder wiser when predicting future actions and events? Journal of Personality and Social Psychology 61: 521-532.

Fischhoff B, Slovic P, Lichtenstein S (1977) Knowing with certainty. The appropriateness of extreme confidence. Journal of Experimental Psychology: Human Perception and Performance 3: 552-564.

Fletcher GF, Balady G, Froelicher VF, Hartley LH, Haskell WL, Pollock ML (1995) Exercise standards. A statement for healthcare professionals from the American Heart Association. Writing Group. Circulation 91: 580-615.

Franken S (2016) Führen in der Arbeitswelt der Zukunft. [Leadership in the future working world]. Wiesbaden, Springer Fachmedien Wiesbaden.

Friedrich J (1996) On Seeing Oneself as Less Self-Serving Than Others. The Ultimate Self-Serving Bias? Teaching of Psychology 23: 107-109. 
Godino JG, Watkinson C, Corder K, Sutton S, Griffin SJ, van Sluijs EMF (2014) Awareness of physical activity in healthy middle-aged adults: a cross-sectional study of associations with sociodemographic, biological, behavioural, and psychological factors. BMC Public Health 14: 421.

Hayward MLA, Rindova VP, Pollock TG (2004) Believing one's own press. The causes and consequences of CEO celebrity. Strategic Management Journal 25:637-653.

Holtermann A, Marott JL, Gyntelberg F, Søgaard K, Mortensen OS, Prescott E. et al.(2015) Self-reported cardiorespiratory fitness: prediction and classification of risk of cardiovascular disease mortality and longevity--a prospective investigation in the Copenhagen City Heart Study. Journal of the American Heart Association 4: e001495.

Jedlicka et al. (n.d.): Validity and reliability of a new self-report instrument for measuring health, health-related quality of life and physical activity. Mental Health \& Prevention. [under review]

Jung J, Nitzsche A, Ansmann L, Ernstmann N, Ommen O, Stieler-Lorenz Bet al. (2012) Organizational factors and the attitude toward health promotion in German ICTcompanies. Health Promotion International 27: 382-393.

Keith NR, Clark DO, Stump TE, Miller DK, Callahan CM (2014) Validity and reliability of the Self-Reported Physical Fitness (SRFit) survey. Journal of Physical Activity \& Health 11: 853-859.

Kienbaum Management Development (2017) Future Management Development Studies 2017. Retrieved from http://bit.ly/2s9niJu. [Accessed 21 June 2017].

Kuhlmann H, Horn S (2016) Integrale Führung. [Integral guidance]. Wiesbaden, Springer Fachmedien Wiesbaden.

Lechner L, Bolman C, van Dijke M (2006) Factors related to misperception of physical activity in The Netherlands and implications for health promotion programmes. Health Promotion International 21: 104-112.

Lechner L, Brug J, De Vries H (1997) Misconceptions of fruit and vegetable consumption. Journal of Nutrition Education 313-320.

Mabe PA, West SG (1982) Validity of self-evaluation of ability. A review and metaanalysis. Journal of Applied Psychology 67: 280-296.

Malmendier U \& Tate G (2003) Who makes acquisitions? A test of the overconfidence hypothesis. Stanford Research Paper 1798.

Marsh HW (1996) Physical Self Description Questionnaire: stability and discriminant validity. Research Quarterly for Exercise and Sport 67: 249-264.

Martinez-Gomez D, Gomez-Martinez S, Ruiz JR, Diaz LE, Ortega FB, Widhalm K et al. (2012) Objectively-measured and self-reported physical activity and fitness in relation to inflammatory markers in European adolescents: the HELENA Study. Atherosclerosis 221: 260-267.

Mikkelsson L, Kaprio J, Kautiainen H, Kujala UM, Nupponen H (2005) Associations between self-estimated and measured physical fitness among 40-year-old men and women. Scandinavian Journal of Medicine \& Science in Sports 15: 329-335.

Monroe CM, Thomas DQ, Lagally K, Cox A (2010) Relation of college students' selfperceived and measured health-related physical fitness. Perceptual and Motor Skills 111: 229-239.

Odean T (1998) Volume, volatility, price, and profit when all traders are above average. Journal of Finance 1887-1934.

Ortega FB, Sanchez-Lopez M, Solera-Martinez M, Fernandez-Sanchez A, Sjostrom M, Martinez-Vizcaino V (2013) Self-reported and measured cardiorespiratory fitness similarly predict cardiovascular disease risk in young adults. Scandinavian Journal of Medicine \& Science in Sports 23: 749-757. 
Plante A, Bouchard L (1996) Occupational Stress, Burnout, and Professional Support in Nurses Working with Dying patients. Omega 32: 93-109.

Prince SA, Adamo KB, Hamel ME, Hardt J, Connor Gorber S, Tremblay M (2008) A comparison of direct versus self-report measures for assessing physical activity in adults: a systematic review. The International Journal of Behavioral Nutrition and Physical Activity 5: 56.

Ronda G, van Assema P, Brug J (2001) Stages of change, psychological factors and awareness of physical activity levels in The Netherlands. Health Promotion International 16: 305-314.

Rudolf K, Schaller A, Frick F, Grieben C, Froböse I (2016) Erfassung der Selbsteinschätzung körperlicher Aktivität von jungen Erwachsenen. [Assessment of self-assessment of physical activity of young adults]. Prävention und Gesundheitsförderung 11: 20-26.

Schaller A, Rudolf K, Dejonghe L, Grieben C, Froboese I (2016) Influencing Factors on the Overestimation of Self-Reported Physical Activity: A Cross-Sectional Analysis of Low Back Pain Patients and Healthy Controls. BioMed Research International, 2016, 1497213.

Schulte PA, Guerin RJ, Schill AL, Bhattacharya A, Cunningham TR, Pandalai SP et al. (2015) Considerations for Incorporating "Well-Being" in Public Policy for Workers and Workplaces. American Journal of Public Health 105: 44.

Tanaka H, Monahan KD, Seals DR (2001) Age-predicted maximal heart rate revisited. Journal of the American College of Cardiology 37: 153-156.

van Sluijs EM, Griffin SJ, van Poppel MN (2007) A cross-sectional study of awareness of physical activity: associations with personal, behavioral and psychosocial factors. The International Journal of Behavioral Nutrition and Physical Activity 4: 53.

van Weering MGH, Vollenbroek-Hutten MMR, HermensHJ (2011) The relationship between objectively and subjectively measured activity levels in people with chronic low back pain. Clinical Rehabilitation 25: 256-263.

Vassiliadis A (1999) Zur Methodik der Ausdauerdiagnostik beim Mittel- und Langstreckenlauf [Methodology of endurance diagnostics in middle-distance and long-distance running]. Köln, Sport und Buch Strauss.

Watkinson C, van Sluijs EM, Sutton S, Hardeman W, Corder K, Griffin SJ (2010) Overestimation of physical activity level is associated with lower BMI: a crosssectional analysis. The International Journal of Behavioral Nutrition and Physical Activity 7: 68. 
